\title{
Depression in adolescence
}

\author{
Prof Anita Thapar, FRCPsych, Stephan Collishaw, DPhil, Daniel S Pine, MD, and Ajay K \\ Thapar, PhD \\ Child \& Adolescent Psychiatry Section, Department of Psychological Medicine and Neurology \\ (Prof A Thapar FRCPsych, S Collishaw DPhil, A K Thapar PhD), and MRC Centre for \\ Neuropsychiatric Genetics and Genomics (A Thapar, S Collishaw), School of Medicine, Cardiff \\ University, Cardiff, Wales, UK; Emotion and Development Branch, NIMH-Intramural Research \\ Program, Bethesda, MD, USA (D S Pine MD); and Taff Riverside Practice, Cardiff, Wales, UK (A \\ K Thapar)
}

\section{Abstract}

Unipolar depressive disorder in adolescence is common worldwide but often unrecognised. The incidence, notably in girls, rises sharply after puberty and, by the end of adolescence, the 1 year prevalence rate exceeds $4 \%$. The burden is highest in low-income and middle-income countries. Depression is associated with sub stantial present and future morbidity, and heightens suicide risk. The strongest risk factors for depression in adolescents are a family history of depression and exposure to psychosocial stress. Inherited risks, developmental factors, sex hormones, and psychosocial adversity interact to increase risk through hormonal factors and associated perturbed neural pathways. Although many similarities between depression in adolescence and depression in adulthood exist, in adolescents the use of antidepressants is of concern and opinions about clinical management are divided. Effective treatments are available, but choices are dependent on depression severity and available resources. Prevention strategies targeted at high-risk groups are promising.

\section{Introduction}

Unipolar depressive disorder is a common mental health problem in adolescents worldwide, ${ }^{1}$ with an estimated 1 year prevalence of $4-5 \%$ in mid to late adolescence. ${ }^{2,3}$ Depression in adolescents is a major risk factor for suicide, the second-to-third leading cause of death in this age group, ${ }^{4}$ with more than half of adolescent suicide victims reported to have a depressive disorder at time of death. ${ }^{5}$ Depression also leads to serious social and educational impairments, ${ }^{6,7}$ and an increased rate of smoking, substance misuse, and obesity. ${ }^{8,9}$ Thus, to recognise and treat this disorder is important.

Depression is defined as a cluster of specific symptoms with associated impairment. The clinical and diagnostic features of the disorder are broadly similar in adoles cents and adults (panel). ${ }^{10,11}$ The two main classification systems (international classification of diseases- 10 [ICD-10] and the American diagnostic and statistical manual of mental disorders-IV [DSMIV]) define depression similarly, although DSM-IV makes one exception for children and adolescents, whereby irritable rather than depressed mood is allowed as a core diagnostic

Correspondence to: Prof Anita Thapar, Child \& Adolescent Psychiatry Section, Department of Psychological Medicine and Neurology, School of Medicine, Cardiff University, Heath Park, Cardiff CF14 4XN, Wales, UK, thapar@Cardiff.ac.uk.

Contributors

All authors contributed to the research, interpretation of research, writing, and editing of the manuscript.

Conflicts of interest

We declare that we have no conflicts of interest. 
symptom. ${ }^{12}$ Nevertheless, depression in adolescents is more often missed than it is in adults, ${ }^{13}$ possibly because of the prominence of irritability, mood reactivity, and fluctuating symptoms in adolescents. Depression can also be missed if the primary presenting problems are unexplained physical symptoms, eating disorders, anxiety, refusal to attend school, decline in academic performance, sub stance misuse, or behavioural problems.

In some respects depression in adolescents can be viewed as an early-onset subform of the equivalent adult disorder because of its strong links with recurrence later in life. ${ }^{14}$ The illness has similar clinical features and patterns of neural activity to that in adults, and its occurrence is also associated with a family history of the disorder. ${ }^{11}$ However, important differences exist between the two disorders, particularly in treatment response, with strongly divided opinions about best treatment practices. ${ }^{10}$ Depression in prepubertal children is less common than depression in adolescents or adults, and seems to differ from these disorders with respect to some causative, epidemiological, and prognostic features. ${ }^{15,16}$

We focus on unipolar depression in adolescents. When evidence is available, we focus on depressive disorder rather than its symptoms. However, in some instances, the only available data are based on studies in which depressive symptoms are reported. Such cases are noted, although there are generally strong similarities in research findings for depressive symptoms and depressive disorder.

\section{Epidemiology}

The prevalence of depression in children is low $(<1 \% \text { in most studies })^{17}$ with no sex differences, and then rises substantially throughout adolescence. ${ }^{18}$ Many factors could explain the recorded post-pubertal rise in prevalence because adolescence is a developmental period characterised by pronounced biological and social changes. ${ }^{19,20}$ The most commonly postulated contributors are puberty and brain and cognitive maturation. They include enhanced social understanding and self-awareness, ${ }^{21}$ changes in brain circuits involved in responses to reward and danger, and increased reported stress levels, especially in girls. ${ }^{22,23}$ Median 12-month prevalence estimates in mid to late adolescence are roughly similar to those seen in adulthood (4-5\%), ${ }^{2,3}$ with the cumulative probability of depression rising from around $5 \%$ in early adolescence to as high as $20 \%$ by the end of that time. ${ }^{24,25}$ However, population prevalence estimates vary widely across studies (table) and in different countries, $, 129,30$ possibly because of methodological differences.

Patterns of service provision vary so much between studies and countries that comparisons of clinic-referred samples are not meaningful. Although some researchers suggest higher rates of depression in adolescents in low-income and middle-income countries,${ }^{29}$ no consistent evidence of such systematic variation exists. ${ }^{1,29,30}$ Nevertheless, because of the young age distribution in low-income and middle-income countries, the overall number of affected adolescents will be substantially greater in these countries than in high-income countries. ${ }^{1}$ Despite this high burden, research has focused almost exclusively on highincome countries.

One of the most robust epidemiological findings is the emergence of a strong female preponderance (about 2:1) in the prevalence of depression in adolescents after puberty. ${ }^{31}$ The excess of affected girls is seen in epidemiological as well as clinical samples, and is robust across different methods of assessment. Sex differences in rates of depression are therefore unlikely to be merely due to differences in help-seeking or reporting of symptoms. Although the reasons for this post-pubertal-onset sex difference are not fully understood, adolescent depression is more closely tied to female hormonal changes than to chronological age, which suggests that depression is directly linked to pubertal changes in hormone-brain relations. ${ }^{32}$ However, hormonal changes alone rarely produce the behavioural or neural 
signs of depression, ${ }^{33}$ and are more likely to contribute by sensitising the brain to the harmful effects of stress. ${ }^{31,34,35}$ Work in animals shows that oestrogen increases the stress response in the prefrontal cortex. ${ }^{36}$ Thus, the post-pubertal sex difference in depression might in part result from increased exposure to stressors and hormonally-linked heightened stress sensitivity in girls. Finally, although depression is generally more common in girls, to recognise it in boys is important. Moreover, in some subgroups (eg, patients with neurodevelopmental and medical disorders) this sex difference might be greatly weakened, absent, or even reversed. ${ }^{37}$

Changes in taxonomy and assessment methods pre clude strong conclusions about whether or not the true prevalence of depressive disorder in adolescents has changed over time. ${ }^{38}$ Certainly, the use of depression services and recognition of the disorder have increased, as has treatment in many countries. ${ }^{39}$ Youth suicide rates have fluctuated over the same period. ${ }^{40}$ One meta-analysis found no evidence of an increase in rates of depressive disorder in adolescents between 1965 and $1995 .{ }^{3}$ However, comparisons of identical symptom screens across repeated epidemiological cohorts have shown evidence of increasing rates of depression and anxiety symptoms in some countries. ${ }^{38}$

\section{Clinical outcomes of depression in adolescents}

Longitudinal studies of community and clinic-based population samples suggest that 60 $90 \%$ of episodes of depression in adolescents remit within a year. ${ }^{41,42}$ However, in followup studies $50-70 \%$ of patients who remit develop subsequent depressive episodes within 5 years. ${ }^{41,43}$ Clinic-referred patients generally fare less well than those treated in the community. ${ }^{6}$ Moreover, in adults very few individuals show complete symptomatic and functional recovery between depressive episodes, with most reporting residual symptoms or impairment. ${ }^{44,45}$

Finally, depression in adolescence also predicts a range of mental health disorders in adult life-notably, anxiety disorders, substance-related disorders, and bipolar disorder, ${ }^{46-48}$ as well as suicidal behaviour, unemployment, ${ }^{48}$ and physical health problems. ${ }^{49}$ Thus, an episode of depression during adolescence often heralds a chronic or relapsing disorder, and forecasts a broad range of psychosocial difficulties and ill health.

\section{Cause and pathogenenesis}

Because of the clinically heterogeneous and diverse causes of the illness, to understand the pathogenesis of depression in adolescents is challenging. Like many other common health disorders, several risk factors interact to increase the risk of depression in a probabilistic way. To assess the contribution of any single risk factor in isolation and to identify crucial developmental periods when exposure is especially risky is difficult because many individual, family, and social risks are strongly correlated and relate to continuing and later adversities.

Distal risks such as inherited factors and adversity in early life might directly and indirectly predispose to depression. Such risks could mediate their effects through temperament and personality attributes (negative emotionality, decreased positive emotionality and attentional control, behavioural inhibition, and neuroticism) and cognition. ${ }^{50}$ However, consistent evidence is sparse as to whether such characteristics are risk factors, mediators, or consequences of depression.

Distal factors, together with hormonal and maturational changes can also alter individual sensitivity to stressors. These risk factors in turn affect proximal biological risk mechanisms such as changes to the neuroendocrine system and brain structure and function, although no 
one pathway has been identified as causal. Prevention and treatments have been targeted at reduction of early and later adversities, modification of ways of thinking and feeling, and reduction of core depression symptoms by alteration of biological pathways with medication.

\section{Familial and genetic risk}

Off spring of parents who have depression face three to four times increased rates of depression compared with off spring of healthy parents. ${ }^{51}$ Both genes and non-inherited factors contribute to this risk. ${ }^{51,52}$ Although exposures to maternal depression in the prenatal and postnatal periods have been regarded as especially important, ${ }^{53}$ unlike in animals, evidence that risks to off spring are restricted to these crucial periods is inconsistent. Longitudinal research, ${ }^{54,55}$ studies of children who are genetically unrelated to their mothers, ${ }^{52,56}$ and treatment trials of maternal depression ${ }^{57}$ suggest that the risk effects of early maternal depression are mediated through exposure to later, continued maternal symptoms or associated psychosocial adversity. ${ }^{58}$ Although the importance of paternal mental health is now starting to be recognised ${ }^{59}$ the long-term effects on depression during adolescence have yet to be investigated.

Inherited factors also play a part. Most twin studies show that depression becomes increasingly heritable from childhood (zero to low heritability) to late adolescence (modest heritability, around 30-50\%). ${ }^{60}$ The heritability rates during late adolescence are similar to those seen in adult life. ${ }^{60,61}$ Inherited liability for depression manifests in different ways and at different times. Family and twin studies ${ }^{60}$ suggest that anxiety and depression share inherited liability, but anxiety in childhood tends to precede later depression during adolescence. Some genetic risks are shared with disruptive behaviour problems. ${ }^{62,63}$ Several workers have suggested that adolescent-onset depression, like other early-onset forms of illness, such as breast cancer, represents a more strongly genetic subform of depression, ${ }^{64}$ but consistent evidence is scarce. ${ }^{65}$

Some studies have focused on identifying specific genes that increase susceptibility for unipolar depression. So far, no replicated, significant findings have emerged. ${ }^{66,67}$ These negative findings for unipolar depression contrast with those for other psychiatric disorders such as schizophrenia and bipolar disorder, perhaps because genes operate in more complex ways for depressive disorder than we currently understand, or because optimum genetic research strategies have not been used.

\section{Psychosocial risk factors}

Much research has been done into the association between depression and environmental factors such as exposures to acute stressful events (eg, personal injury, bereavement) ${ }^{68,69}$ and chronic adversity (eg, maltreatment, family discord, bullying by peers, poverty, physical illness). Nevertheless, such exposures do not always lead to the development of depression in adolescents, although those at high genetic risk seem to be especially susceptible to the effects of such stressors. ${ }^{70}$ Stressful life events seem more strongly associated with first onset rather than recurrence of depression, ${ }^{71}$ and risk is considerably greater in girls, ${ }^{29,72}$ and in adolescents who have multiple negative life events than those exposed to one event. ${ }^{71}$ Chronic, severe stressors that affect relationships seem most important. Negative family relationships ${ }^{73,74}$ peer victimisation through bullying, ${ }^{75}$ and maltreatment are common risks for depression.

Some children exposed to the traumatic events of war, torture, displacement, orphanhood, or HIV infection ${ }^{76,77}$ might develop long-term psychiatric disorders, especially if there is a family history of such disorders, or they are exposed to multiple traumas. ${ }^{78}$ Although 
recorded associations between psychosocial stressors and depression could show the effects of unmeasured confounders and reverse causation, findings with different research designs consistently show genuine causal risk effects.

\section{Gene-environment interplay}

Inherited factors seem to contribute to depression in adolescents in two ways-not only by directly increasing risk, but also indirectly through gene-environment interplay, specifically by increasing sensitivity to adversity (gene-environment interaction) and by increasing the probability of exposure to risky environments (gene-environment correlation). ${ }^{60,79,80}$ Several twin and family studies suggest that adolescents (especially girls) at high inherited and familial risk of depression show increased sensitivity to psychosocial risk factors (geneenvironment interaction), such as stressful life events ${ }^{81}$ and family adversity, ${ }^{60,80}$ and are the ones most likely to be exposed to such risks. ${ }^{80}$

Do specific gene variants moderate the effects of adversity on brain function and clinical outcome? Many reports suggest that a variant (5-HTTLPR) in the serotonin transporter gene might increase risk of depression, but only in the presence of adverse life stressors or early maltreatment. ${ }^{82,83}$ The findings are less robust in adolescent boys than in girls. ${ }^{83}$ Importantly, this same gene variant has also been reported to affect fear-related and dangerrelated brain circuitry that is altered in depression; specifically it is associated with increased amygdala activation in healthy individuals in response to viewing fearful faces ${ }^{84}$ However, such findings in relation to depression and depression-related brain mechanisms seem to vary not only by genotype, but also by age, sex, and severity of symptoms, and are also reliant on good quality measures of adversity and depression. Although one meta-analysis failed to support the 5-HTTLPR gene-environment interaction finding, ${ }^{85}$ it was criticised on many grounds, ${ }^{83,86}$ and a re-analysis of data showed significant evidence of the importance of gene-environment interactions, especially in the context of maltreatment or a medical illness. ${ }^{87}$ Thus, although thought to be controversial by some researchers, ${ }^{85}$ these findings are promising.

\section{Brain and neuroendocrine mechanisms}

Both inherited factors and psychosocial stressors can be thought of as distal risk factors, which determine the risk for depression by shaping more proximal biological mechanisms such as activity in underlying neural circuits and endocrine systems. ${ }^{88}$ The similarity of findings in adolescents and adults suggests that core biological features are shared.

Work in animals not only has shown that the immature, adolescent brain is more susceptible than the adult brain to the effects of these genetic and environmental influences, ${ }^{89,90}$ but has also identified specific brain regions where changes in circuitry occur. ${ }^{90}$ Moreover, these regions seem to be the same ones implicated in human brain imaging studies. Two interrelated neural circuits and associated modulatory systems have been closely linked to risk for depression, both in adults and in adolescents. These circuits are active in the response to danger and learning about rewards. ${ }^{91,92}$

One circuit connects the amygdala to the hippocampus and ventral expanses of the prefrontal cortex (PFC) and is linked to hypothalamic-pituitary-adrenal (HPA) axis activity. Activity in this circuit consistently seems raised in patients with major depression, and both established and novel treatments for depression could work through reduction of its activity. ${ }^{93}$ Some of these neural changes are also seen in healthy, at-risk individuals, such as in those with particular temperament types (behaviourally inhibited) ${ }^{94,95}$ and those at high familial and genetic risk for depression. ${ }^{94}$ Perturbations in this circuit link depression to 
stress-related enhancements in HPA-stress systems, such as higher than expected cortisol concentrations, ${ }^{96,97}$ and activity in the serotonergic system.

Genetic factors, psychosocial stress, sex hormones, and development have also been linked to changing activity in this circuit, ${ }^{84,94}$ with evidence that this circuit matures after adolescence. High concentrations of sex steroid receptors have been identified within this circuit, ${ }^{23}$ and might provide a biological mechanism for why girls have higher risk of depression than boys.

The other key circuit implicated in depression encompasses the striatum and its connection to both the PFC and ventral dopamine-based systems. Like the first circuit, this one also continues to mature through adolescence. Sex differences emerge in both circuits. ${ }^{98}$ Research into this reward circuit implies that reduced activity is linked with expression of and risk for depression. Reduced striatal and PFC activity during tasks involving rewards has been recorded both in individuals with major depression and in those with depressed parents. ${ }^{99}$ Both inherited factors and stress-related perturbations seem to contribute to these changes. ${ }^{100}$

\section{Resilience}

Many children who are at high-risk for depression through familial predisposition and exposure to adversity do not develop the disorder. ${ }^{101}$ Research into depression resilience has the potential to identify targets for prevention of depression. Individual factors that have been reported to protect against the development of depression in high-risk adolescents include inherited factors and high intelligence, as well as potentially modifiable factors such as emotion-regulation capacities, coping mechanisms, and thinking styles. ${ }^{102-105}$ The most consistent findings relate to the protective effects of good quality interpersonal relationships, suggesting that improvement of these relationships could be a target for prevention of depression. Children with a high familial risk of depression tend to have better mental health if their relationships with their parents are characterised by warmth, acceptance, low hostility, and low parental control. ${ }^{102,105}$ The broader social context also needs to be considered because quality of peer support seems especially predictive of resilience to depression in the context of child maltreatment and maternal depression. ${ }^{103-105}$

However, factors that enhance resilience to depression vary considerably between different groups of children and across diverse risk contexts, which means that prevention strategies will probably need to be carefully tailored for maximum benefit. ${ }^{101}$ Also, studies have tended to focus on correlates of resilience, and underlying mechanisms remain poorly understood. Whether or not targeted interventions aimed at promoting children's resilience to depression prove successful needs to be assessed.

\section{Detection and diagnosis}

A diagnostic approach is needed when decisions about treatment of adolescents with depression have to be made. This approach allows clinicians to apply evidence from treatment trials, make decisions on the risk-benefit ratio for medication, and rationalise referral to expensive specialist resources (if available). Depression can also be thought of as lying along a continuum. ${ }^{106}$ Subsyndromal depression in which adolescents have high levels of symptoms that do not meet the diagnostic threshold for depressive disorder predicts concurrent impairment and future risk. ${ }^{46,106}$ Longitudinal studies of adolescents with subsyndromal depression show that they are at increased risk of later full-blown depressive disorder. ${ }^{43,46,107}$ Thus, there are important reasons for paying attention to sub-syndromal depression, and targeting individuals with these symptoms for prevention, low-risk intervention strategies, and lifestyle changes. ${ }^{108}$ 
Since depression is under-diagnosed, professionals caring for adolescents need to be aware of the possibility of this diagnosis, particularly in high-risk groups. Figure 1 shows a suggested process for detecting adolescents with depression in primary care, child health clinics, schools, and social care settings. WHO has launched an important initiative to improve the worldwide diagnosis and management of certain key conditions, and a strategy for screening and management of depression has been identified. ${ }^{109}$ Targeted screening of high-risk individuals rather than universal screening of the general population is recommended, ${ }^{110}$ but the value of screening in different settings has yet to be critically assessed.

Questionnaires provide an economical and quick method of screening. The two-item patient health questionnaire (PHQ-2) $)^{111}$ is a brief measure widely used to screen for depression in adults in primary care, and studies have shown it also works well for adolescents. ${ }^{112,113}$ The full 25-item strength and difficulties questionnaire (SDQ) provides additional screens for attention deficit hyperactivity disorder (ADHD) and disruptive behaviour symptoms. ${ }^{114}$ Other measures focus on depression alone and include the short mood and feelings questionnaire, ${ }^{115}$ and the children's depression inventory. ${ }^{116}$ These questionnaires can be used as an additional screen in adolescents if there is some uncertainty about the reliability of the responses to the PHQ-2 or SDQ items, and as an adjunct to monitor change (figure 1).

For individuals who score above the cutoff scores a full clinical assessment should be undertaken to reliably diagnose depression. This assessment consists of sensitive, empathic questioning about symptoms of depression (panel), their duration, severity, and any associated impairment through a direct interview with the adolescent. It might be necessary to interview them separately from accompanying adults for part of the consultation. Information provided by a parent or guardian is important because diagnoses based on the accounts of several informants show greater reliability and validity. ${ }^{117}$ The risk of suicide and how the adolescent functions at home and school should be assessed. Possible warning signs include a decline in academic achievement or engagement in leisure activities, changes in peer and family relationships, and social withdrawal. The best strategy for clinical assessment by non-specialists has yet to be determined. Training programmes to improve detection and diagnosis of depression have not proved consistently successful. An alternative strategy would be to assess the use of standardised structured diagnostic interviews such as the freely available development and well being assessment. ${ }^{118}$

\section{Differential diagnoses and comorbidities}

Two diagnoses in classification systems that are characterised by prominent depressive symptoms and associated impairment but that do not meet the criteria to diagnose major depression are adjustment disorder and dysthymic disorder. Research into the validity and treatment of these disorders is sparse. Adjustment disorder is short-lived, arises within 3 months of the onset of a stressor and does not persist longer than 6 months after the desistance of the stressor. Dysthymic disorder describes a pattern of chronic symptoms of depression that are present for most of the time on most days with a minimum duration of 1 year for children and adolescents. Sometimes individuals with dysthymic disorder have superimposed episodes of major depression onto their usual symptoms.

Although bipolar disorder and schizophrenia are much less common in adolescents than is unipolar depression (prevalence is $<0 \cdot 1-1 \%$ for both), ${ }^{19-121}$ they are important differential diagnoses to be remembered. Both disorders can be preceded or accompanied by depression or symptoms of depression, but they have other key features - such as episodic elated or irritable mood or enhanced energy in bipolar disorder-that do not occur in major depression. Treatment is very different for the three conditions. Patients with bipolar disorder can also present, like patients with depression, with agitation and irritability. 
Chronic non-episodic irritability which is a core feature of a recently defined syndrome of severe mood dysregulation is not the same as bipolar disorder, but seems to be a strong predictor of future depression. ${ }^{122}$

Two-thirds of adolescents with depression have at least one comorbid psychiatric disorder and $10-15 \%$ have two or more comorbidities. ${ }^{28}$ Adolescents with depression are six to 12 times more likely to have anxiety, four to 11 times more likely to have a disruptive behaviour disorder, and three to six times more likely to have a substance misuse problem than are adolescents who are not depressed, with adjustment for multiple comorbidities. ${ }^{123}$ For example, almost $20 \%$ of adolescents with depression also meet diagnostic criteria for generalised anxiety disorder, ${ }^{124}$ with reported lifetime rates of $50-70 \% .{ }^{125}$ Depression can also complicate eating disorders, autistic spectrum disorders, and ADHD.

Comorbidity is especially increased in adolescents with severe depression, ${ }^{126}$ and predicts severe impairment, poor long-term outcome, ${ }^{126}$ and complicates treatment. ${ }^{127}$ The high level of comorbidity can be explained in part by shared risk factors for multiple disorders, but could also arise if comorbid disorders are risks or consequences of depressive disorder. When a patient with a depressive disorder also has another psychiatric disorder, the depression should be treated in its own right, with the understanding that additional interventions will be needed to address the specific comorbidity. Patients with medical illnesses such as diabetes or HIV/AIDS can have comorbid depression. The value of distinguishing between primary and secondary depression in the context of another disorder is not clear because there is growing evidence that the relation between medical illness and depression is often bi-directional, ${ }^{128}$ and treatment of depression is still needed. The extent to which different comorbidities might be associated with heterogeneity in cause, prognosis, and treatment remains unclear.

\section{Treatment}

Treatment data in adolescents have been reviewed (figure 2). ${ }^{10,129}$ Three important issues are highlighted. First, treatment choices are not the same in adolescents as in adults. Second, best treatment practice is controversial because accepted practice and clinical guidelines vary in different countries, and because of concerns about the use of antidepressant drugs in patients younger than 18 years, with some recommendations based on consensus rather than on evidence. Third, the evidence relates to the short-term effectiveness of psychological treatments and medication. Evidence for the long-term benefits of treatment to rates of recurrence and for the effectiveness of non-specialist interventions is scarce.

The two best studied psychological treatments are cognitive behavioural therapy (CBT) and interpersonal psychotherapy (IPT). There have been two published meta-analyses of CBT (based on 35 trials in children and adolescents, ${ }^{130}$ and 11 in adolescents only ${ }^{131}$ ). Both recorded that CBT was an effective treatment, but neither showed an effect size greater than $0 \cdot 3$, which is the lower limit for a moderately effective treatment. ${ }^{130,131}$ The largest randomised controlled trial (RCT) of adolescents with moderate to severe depression showed similar response rates in the CBT and placebo groups (43\% vs $35 \%),{ }^{42}$ although another large study noted that the addition of CBT to antidepressant medication was beneficial in treatment-resistant depression. ${ }^{132}$ Overall, the data suggest that CBT is probably effective in adolescents with milder forms of depression, but it fails to consistently produce more beneficial effects than do control treatments in those with moderate to severe depression, which has raised some questions on applicability and who is most likely to benefit.

Three RCTs suggest that IPT is a useful treatment. ${ }^{133-135}$ However, most countries do not have an adequate pool of trained therapists to deliver this treatment. Although in many 
countries, including the UK, simple non-specific psychosocial strategies (figure 2) are recommended as initial treatment for mild depression, there is little good quality evidence of their effectiveness.

Unlike in adults, tricyclic antidepressants are not an effective treatment for adolescents with depression. ${ }^{136}$ Fluoxetine, a selective serotonin reuptake inhibitor, seems effective in metaanalyses ${ }^{137}$ and RCTs ${ }^{42,138,139}$ but evidence is sparse for other antidepressants. RCTs suggest that escitalopram might be effective, ${ }^{140}$ which led the US Food and Drug Administration to approve its use in adolescents. Irrespectively, even in the best circumstances, antidepressants seem no more than moderately effective in adolescents with depression.

Suicidal risk in relation to antidepressant use is controversial. ${ }^{137,141}$ Several studies, including a meta-analysis, suggest a significant association with such risk, ${ }^{137}$ especially in young people. Individuals younger than 25 years of age treated with antidepressants are more likely than older adults to develop thoughts about suicide. However, a large metaanalysis ${ }^{141}$ showed that the benefits of such treatments still outweigh the risks (numbers needed to treat $10 v s$ numbers needed to harm 143). With the mixed evidence and because untreated depression in adolescents is itself so strongly associated with risk of suicide, suicidal risk should be monitored in this clinical group, irrespective of treatment choice. Selective serotonin reuptake inhibitors, notably fluoxetine, can also cause agitation and precipitate hypomanic symptoms in some individuals.

The two largest treatment trials for depression in adolescents have examined the combined benefits of medication and CBT, and although they reached different conclusions, we note that there were differences in sample selection, treatment protocols, and outcome measures.

In the UK Adolescent Depression, Antidepressants, and Psychotherapy Trial (ADAPT) all participants received routine specialist mental health service care. ${ }^{138}$ The addition of CBT to fluoxetine did not improve outcomes. However, the US Treatment for Adolescents with Depression Study (TADS) ${ }^{42}$ showed that 12 weeks of combined treatment with CBT and fluoxetine produced greater improvements than did fluoxetine alone.

Other investigations assessed treatment resistance. One American $\mathrm{RCT}^{132}$ reported that switching from fluoxetine to another antidepressant (paroxetine or citalopram) and the addition of CBT resulted in greater improvement in symptoms than a medication switch alone $(54.8 \%$ vs $40.5 \%)$. A switch to venlafaxine resulted in adverse side-effects (mainly cardiovascular), and was thus not recommended.

The scarcity of access to and availability of some treatments (notably CBT and IPT) for adolescents with depression in non-specialist contexts in many countries is a major concern. One RCT in the USA showed that the use of primary care-based case-managers who supported clinicians' management of depression and delivered CBT when required led to a significant improvement in symptoms of depression in adolescents. ${ }^{142}$ Counselling programmes in schools and primary care are being introduced in some countries that could offer a more pragmatic way of initially dealing with mild or sub-threshold depression in adolescents and improve access to treatment for this group. ${ }^{143}$ Other less expensive approaches that could also be used in primary care, delivered through the internet or by nonspecialists are now being investigated for use in adults with depression, but have not yet been widely assessed for adolescents.

A report by a special WHO panel has drawn attention to the importance of treatment of mental health disorders in low-income and middle-income countries where resources are scarce, with depression in adolescents identified as a key priority area. ${ }^{144,145}$ One promising 
approach is the treatment of mental health problems in children exposed to traumatic events with IPT delivered by trained local community workers. A well designed, RCT examined the efficacy of IPT in adolescent survivors of war and displacement in northern Uganda. The study recorded that IPT delivered by local community workers significantly improved symptoms of depression in adolescent girls. ${ }^{146}$

\section{Prevention}

In view of the disability associated with depression in adolescents, prevention or at least delay of onset of the disorder is important. ${ }^{101,129}$ Prevention strategies could be aimed at reduction of modifiable risks and promotion of factors to protect high-risk children from the effects of adversity and interrupting risk pathways. Prevention methods have been much discussed in an Institute of Medicine report and a meta-analysis. ${ }^{101,147}$ Both concluded that a targeted and indicated prevention strategy is effective in preventing the development of depression in adolescents whereas universal prevention is not.

Government policies that address social inequalities are potentially important but consistent evidence of reduced rates of depression in adolescents in countries with few inequalities is scarce. Some countries have introduced prenatal and preschool (age 0-5 years) child development programmes that aim to provide support, reduce early adversities, enhance early stimulation at home, and improve parenting in high-risk families. ${ }^{101}$ Such prevention strategies seem to have some immediate and continued positive effects on cognitive ability and antisocial behaviour, but consistent evidence with regard to prevention of depressive disorder in adolescents is scarce.

Depression-specific prevention strategies consist of a combination of education about depression and CBT strategies applied to children and parents. These strategies have been targeted at three risk groups - the off spring of parents who have had depression, adolescents with subthreshold symptoms of depression, and adolescents who have had a previous depressive episode. A large RCT showed that a group CBT programme reduced the incidence of depression in treated adolescents after 1 year compared with an untreated group $(21.4 \%$ vs $32.7 \%) .{ }^{148}$ However, the prevention was less effective in those who had a parent with current depression. This result, coupled with that of a treatment study of adult depression showing that remission of maternal depression was associated with benefits to their off spring's mental health, ${ }^{57}$ suggests that effective treatment of parental depression is important for the adolescent with depression. Preliminary evidence from a systematic review suggests that school-based CBT-oriented prevention is a promising approach (reported effect sizes of 0.21-1.40) when targeted at adolescents who report high rates of depression symptoms. ${ }^{149}$

Although there is less research on depression to inform practice in low-income and middleincome countries than in more developed countries, ${ }^{150}$ interventions such as training in positive thinking and conflict resolution have been noted to reduce the rate of depressive symptoms. ${ }^{151}$ Other strategies such as parenting programmes have also been developed, which might be of particular importance in view of the high rates of maternal depression worldwide and parenting problems in these circumstances, although consistent evidence for reduced rates of adolescent depression outcomes is scarce. ${ }^{152}$ These approaches and psychological therapies such as IPT could be especially helpful for those children exposed to trauma and identified as belonging to a high risk group, ${ }^{78}$ but have not been widely studied in a preventive context. Quality of relationships seems key to enhance resilience in high-risk children. Thus far not all prevention programmes have targeted this issue. 


\section{Conclusion}

Despite the global importance of depression in adolescence, many knowledge gaps exist. Further development of pragmatic, cost-effective methods of detecting, assessing, and treating adolescent depression in non-specialist contexts and low-income and middle-income countries is an important priority in view of the scarcity of resources. The knowledge gap with regard to relapse prevention is also noticeable. Finally, prevention strategies seem important because of the complexities and costs associated with treatment of depression in adolescents. However, what the key components of these programmes and policies ought to be is not yet clear. Cost effectiveness must also be determined. Such strategies need to be a priority for future research.

\section{Acknowledgments}

The authors' research on depression is funded by the Sir Jules Thorn Charitable Trust. SC is supported by the Waterloo Foundation. We thank Sir Michael Rutter, Antonio Munoz, Robert Potter, Gemma Lewis, and Miriam Cooper for comments on an earlier draft, Robert Goodman for advice, and Peter MacSorley (medical student) for assistance with the literature search.

\section{References}

1. Lopez, A.; Mathers, C.; Ezzati, M.; Jamison, D.; Murray, C. Global burden of disease and risk factors. Washington: Oxford University Press and the World Bank; 2006.

2. Costello EJ, Egger H, Angold A. 10-year research update review: the epidemiology of child and adolescent psychiatric disorders: I. Methods and public health burden. J Am Acad Child Adolesc Psychiatry. 2005; 44:972-86. [PubMed: 16175102]

3. Costello EJ, Erkanli A, Angold A. Is there an epidemic of child or adolescent depression? J Child Psychol Psychiatry. 2006; 47:1263-71. [PubMed: 17176381]

4. Windfuhr K, While D, Hunt I, et al. National confidential inquiry into suicide and homicide by people with mental illness. Suicide in juveniles and adolescents in the United Kingdom. J Child Psychol Psychiatry. 2008; 49:1155-65. [PubMed: 19017029]

5. Hawton K, van Heeringen K. Suicide. Lancet. 2009; 373:1372-81. [PubMed: 19376453]

6. Lewinsohn PM, Rohde P, Seeley JR. Major depressive disorder in older adolescents: prevalence, risk factors and clinical implications. Clin Psychol Rev. 1988; 18:765-94. [PubMed: 9827321]

7. Fletcher JM. Adolescent depression and educational attainment: results using sibling fixed effects. Health Econ. 2008; 17:1215-35. [PubMed: 18157910]

8. Keenan-Miller D, Hammen CL, Brennan PA. Health outcomes related to early adolescent depression. J Adolesc Health. 2007; 41:256-62. [PubMed: 17707295]

9. Hasler G, Pine DS, Kleinbaum DG, et al. Depressive symptoms during childhood and adult obesity: the Zurich cohort study. Mol Psychiatry. 2005; 10:842-50. [PubMed: 15838533]

10. Thapar A, Collishaw S, Potter R, Thapar AK. Managing and preventing depression in adolescents. BMJ. 2010; 340:c209. [PubMed: 20097692]

11. Lewinsohn PM, Pettit JW, Joiner TE Jr, Seeley JR. The symptomatic expression of major depressive disorder in adolescents and young adults. J Abnorm Psychol. 2003; 112:244-52. [PubMed: 12784834]

12. American Psychiatric Association. Diagnostic and statistical manual of mental disorders. 4. Washington DC: American Psychiatric Association; 1994.

13. Leaf PJ, Alegria M, Cohen P, et al. Mental health service use in the community and schools: results from the four-community MECA Study. Methods for the epidemiology of child and adolescent mental disorders study. J Am Acad Child Adolesc Psychiatry. 1996; 35:889-97. [PubMed: 8768348]

14. Birmaher B, Williamson DE, Dahl RE, et al. Clinical presentation and course of depression in youth: does onset in childhood differ from onset in adolescence? J Am Acad Child Adolesc Psychiatry. 2004; 43:63-70. [PubMed: 14691361] 
15. Thapar A, McGuffin P. A twin study of depressive symptoms in childhood. Br J Psychiatry. 1994; 165:259-65. [PubMed: 7953041]

16. Harrington R. Adolescent depression: same or different? Arch Gen Psychiatry. 2001; 58:21-22. [PubMed: 11146754]

17. Kessler RC, Avenevoli S, Ries Merikangas K. Mood disorders in children and adolescents: an epidemiologic perspective. Biol Psychiatry. 2001; 49:1002-14. [PubMed: 11430842]

18. Green, H.; McGinnity, A.; Meltzer, H.; Ford, T.; Goodman, R. Mental health of children and young people in Great Britain, 2004. Basingstoke, UK: Palgrave Macmillan; 2005.

19. Patton GC, Viner R. Pubertal transitions in health. Lancet. 2007; 369:1130-39. [PubMed: 17398312]

20. Cyranowski JM, Frank E, Young E, Shear K. Adolescent onset of the gender difference in lifetime rates of major depression. Arch Gen Psychiatry. 2000; 57:21-27. [PubMed: 10632229]

21. Blakemore SJ. The social brain in adolescence. Nat Rev Neurosci. 2008; 9:267-77. [PubMed: 18354399]

22. Silberg J, Pickles A, Rutter M, et al. The influence of genetic factors and life stress on depression among adolescent girls. Arch Gen Psychiatry. 1999; 56:225-32. [PubMed: 10078499]

23. Nelson EE, Leibenluft E, McClure EB, Pine DS. The social re-orientation of adolescence: a neuroscience perspective on the process and its relation to psychopathology. Psychol Med. 2005; 35:163-74. [PubMed: 15841674]

24. Lewinsohn PM, Rohde P, Klein DN, Seeley JR. Natural course of adolescent major depressive disorder: I. Continuity into young adulthood. J Am Acad Child Adolesc Psychiatry. 1999; 38:5663. [PubMed: 9893417]

25. Hankin BL, Abramson LY, Moffitt TE, Silva PA, McGee R, Angell KE. Development of depression from preadolescence to young adulthood: emerging gender differences in a 10-year longitudinal study. J Abnorm Psychol. 1998; 107:128-40. [PubMed: 9505045]

26. Kessler RC, Walters EE. Epidemiology of DSM-III-R major depression and minor depression among adolescents and young adults in the National Comorbidity Survey. Depress Anxiety. 1998; 7:3-14. [PubMed: 9592628]

27. Costello EJ, Mustillo S, Erkanli A, Keeler G, Angold A. Prevalence and development of psychiatric disorders in childhood and adolescence. Arch Gen Psychiatry. 2003; 60:837-44. [PubMed: 12912767]

28. Ford T, Goodman R, Meltzer H. The British child and adolescent mental health survey 1999: the prevalence of DSM-IV disorders. J Am Acad Child Adolesc Psychiatry. 2003; 42:1203-11. [PubMed: 14560170]

29. Fleitlich-Bilyk B, Goodman R. Prevalence of child and adolescent psychiatric disorders in southeast Brazil. J Am Acad Child Adolesc Psychiatry. 2004; 43:727-34. [PubMed: 15167089]

30. Pillai A, Patel V, Cardozo P, Goodman R, Weiss HA, Andrew G. Non-traditional lifestyles and prevalence of mental disorders in adolescents in Goa, India. Br J Psychiatry. 2008; 192:45-51. [PubMed: 18174509]

31. Hyde JS, Mezulis AH, Abramson LY. The ABCs of depression: Integrating affective, biological, and cognitive models to explain the emergence of the gender difference in depression. Psychol Rev. 2008; 115:291-313. [PubMed: 18426291]

32. Angold A, Costello EJ, Erkanli A, Worthman CM. Pubertal changes in hormone levels and depression in girls. Psychol Med. 1999; 29:1043-53. [PubMed: 10576297]

33. Soares CN, Zitek B. Reproductive hormone sensitivity and risk for depression across the female life cycle: a continuum of vulnerability? J Psychiatry Neurosci. 2008; 33:331-43. [PubMed: 18592034]

34. Angold A, Costello EJ. Puberty and depression. Child Adolesc Psychiatr Clin N Am. 2006; 15:919-37. [PubMed: 16952768]

35. Goodyer IM, Herbert J, Tamplin A, Altham PME. Recent life events, cortisol, dehydroepiandrosterone and the onset of major depression in high-risk adolescents. Br J Psychiatry. 2000; 177:499-504. [PubMed: 11102323]

36. Shansky RM, Glavis-Bloom C, Lerman D, et al. Estrogen mediates sex differences in stressinduced prefrontal cortex dysfunction. Mol Psychiatry. 2004; 9:531-38. [PubMed: 14569273] 
37. van Noorden MS, Giltay EJ, den Hollander-Gijsman ME, van der Wee NJ, van Veen T, Zitman FG. Gender differences in clinical characteristics in a naturalistic sample of depressive outpatients: the Leiden routine outcome monitoring study. J Affect Disord. 2010; 125:116-23. [PubMed: 20051291]

38. Collishaw, S. Trends in adolescent depression: a review of the evidence. In: Yule, W., editor. Depression in childhood and adolescence: the way forward. London: Association of Child and Adolescent Mental Health; 2009. p. 7-18.

39. Ma J, Lee KV, Stafford RS. Depression treatment during outpatient visits by US children and adolescents. J Adolesc Health. 2005; 37:434-42. [PubMed: 16310120]

40. Mittendorfer-Rutz E, Wasserman D. Trends in adolescent suicide mortality in the WHO European Region. Eur Child Adolesc Psychiatry. 2004; 13:321-31. [PubMed: 15490280]

41. Dunn V, Goodyer IA. Longitudinal investigation into childhood- and adolescence- onset depression: psychiatric outcome in early adulthood. Br J Psychiatry. 2006; 188:216-22. [PubMed: 16507961]

42. March J, Silva S, Petrycki S, et al. Treatment for adolescents with depression study (TADS) team. Fluoxetine, cognitive-behavioral therapy, and their combination for adolescents with depression: Treatment for adolescents with depression study (TADS) randomized controlled trial. JAMA. 2004; 292:807-20. [PubMed: 15315995]

43. Lewinsohn PM, Rohde P, Seeley JR, Klein DN, Gotlib IH. Natural course of adolescent major depressive disorder in a community sample: predictors of recurrence in young adults. Am $\mathbf{J}$ Psychiatry. 2000; 157:1584-91. [PubMed: 11007711]

44. Fava GA, Ruini C, Belaise C. The concept of recovery in major depression. Psychol Med. 2007; 37:307-17. [PubMed: 17311684]

45. Conradi HJ, Ormel J, de Jonge P. Presence of individual (residual) symptoms during depressive episodes and periods of remission: a 3-year prospective study. Psychol Med. 2010; 8:1-10. [PubMed: 20932356]

46. Ferguson DM, Horwood LJ, Riddler EM, Beautrais AL. Subthreshold depression in adolescence and mental health outcomes in adulthood. Arch Gen Psychiatry. 2005; 62:66-72. [PubMed: 15630074]

47. Copeland WE, Shanahan L, Costello J, Angold A. Childhood and adolescent psychiatric disorders as predictors of young adult disorders. Arch Gen Psychiatry. 2009; 66:764-72. [PubMed: 19581568]

48. Kim-Cohen J, Caspi A, Moffitt TE, Harrington H, Milne BJ, Poulton R. Prior juvenile diagnoses in adults with mental disorder: developmental follow-back of a prospective-longitudinal cohort. Arch Gen Psychiatry. 2003; 60:709-17. [PubMed: 12860775]

49. Bardone AM, Moffitt TE, Caspi A, Dickson N, Stanton WR, Silva PA. Adult physical health outcomes of adolescent girls with conduct disorder, depression, and anxiety. J Am Acad Child Adolesc Psychiatry. 1998; 37:594-601. [PubMed: 9628079]

50. Garber J. Depression in children and adolescents: linking risk research and prevention. Am J Prev Med. 2006; 31:S104-25. [PubMed: 17175406]

51. Rice F, Harold G, Thapar A. The genetic aetiology of childhood depression: a review. J Child Psychol Psychiatry. 2002; 43:65-79. [PubMed: 11848337]

52. Tully EC, Iacono WG, McGue M. An adoption study of parental depression as an environmental liability for adolescent depression and childhood disruptive disorders. Am J Psychiatry. 2008; 165:1148-54. [PubMed: 18558644]

53. Goodman SH, Gotlib IH. Risk for psychopathology in the children of depressed mothers: a developmental model for understanding mechanisms of transmission. Psychol Rev. 1999; 106:458-90. [PubMed: 10467895]

54. Hammen C, Brennan PA. Severity, chronicity, and timing of maternal depression and risk for adolescent off spring diagnoses in a community sample. Arch Gen Psychiatry. 2003; 60:253-58. [PubMed: 12622658]

55. Hay DF, Pawlby S, Waters CS, Sharp D. Antepartum and postpartum exposure to maternal depression: different effects on different adolescent outcomes. J Child Psychol Psychiatry. 2008; 49:1079-88. [PubMed: 19017024] 
56. Rice F, Harold GT, Boivin J, van den Bree M, Hay DF, Thapar A. The links between prenatal stress and off spring development and psychopathology: disentangling environmental and inherited influences. Psychol Med. 2010; 40:335-45. [PubMed: 19476689]

57. Weissman MM, Pilowsky DJ, Wickramaratne PJ, et al. STAR*D-Child Team. Remissions in maternal depression and child psychopathology: a STAR*D-child report. JAMA. 2006; 295:138998. [PubMed: 16551710]

58. Foster CE, Webster MC, Weissman MM, et al. Remission of maternal depression: relations to family functioning and youth internalizing and externalizing symptoms. J Clin Child Adolesc Psychol. 2008; 37:714-24. [PubMed: 18991123]

59. Ramchandani P, Psychogiou L. Paternal psychiatric disorders and children's psychosocial development. Lancet. 2009; 374:646-53. [PubMed: 19411102]

60. Thapar A, Rice F. Twin studies in pediatric depression. Child Adolesc Psychiatr Clin North Am. 2006; 15:869-81.

61. Kendler KS, Gardner CO, Lichtenstein P. A developmental twin study of symptoms of anxiety and depression: evidence for genetic innovation and attenuation. Psychol Med. 2008; 38:1567-75. [PubMed: 18578897]

62. Rowe R, Rijsdijk FV, Maughan B, Eley TC, Hosang GM, Eley TC. Heterogeneity in antisocial behaviours and comorbidity with depressed mood: a behavioural genetic approach. J Child Psychol Psychiatry. 2008; 49:526-34. [PubMed: 18400059]

63. Cole J, Ball HA, Martin NC, Scourfield J, McGuffin P. Genetic overlap between measures of hyperactivity/inattention and mood in children and adolescents. J Am Acad Child Adolesc Psychiatry. 2009; 48:1094-101. [PubMed: 19797986]

64. Todd RD, Neuman R, Geller B, Fox LW, Hickok J. Genetic studies of affective disorders: should we be starting with childhood onset probands? J Am Acad Child Adolesc Psychiatry. 1993; 32:1164-71. [PubMed: 8282660]

65. Milne BJ, Caspi A, Harrington H, Poulton R, Rutter M, Moffitt TE. Predictive value of family history on severity of illness: the case for depression, anxiety, alcohol dependence, and drug dependence. Arch Gen Psychiatry. 2009; 66:738-47. [PubMed: 19581565]

66. Shyn SI, Shi J, Kraft JB, et al. Novel loci for major depression identified by genome-wide association study of sequenced treatment alternatives to relieve depression and meta-analysis of three studies. Mol Psychiatry. 2011; 16:202-15. [PubMed: 20038947]

67. Shi J, Potash JB, Knowles JA, et al. Genome-wide association study of recurrent early-onset major depressive disorder. Mol Psychiatry. 2011; 16:193-201. [PubMed: 20125088]

68. Goodyer I, Wright C, Altham P. The friendships and recent life events of anxious and depressed school-aged children. Br J Psychiatry. 1990; 156:689-98. [PubMed: 2095946]

69. Pine DS, Cohen P, Johnson JG, Brook JS. Adolescent life events as predictors of adult depression. J Affect Disord. 2002; 68:49-57. [PubMed: 11869782]

70. Hariri AR, Mattay VS, Tessitore A, et al. Serotonin transporter genetic variation and the response of the human amygdala. Science. 2002; 297:400-03. [PubMed: 12130784]

71. Lewinsohn PM, Allen NB, Seeley JR, Gotlib IH. First onset versus recurrence of depression: differential processes of psychosocial risk. J Abnorm Psychol. 1999; 108:483-89. [PubMed: 10466272]

72. Parker G, Brotchie H. Gender differences in depression. Int Rev Psychiatry. 2010; 22:429-36. [PubMed: 21047157]

73. Rueter MA, Scaramella L, Wallace LE, Conger RD. First onset of depressive or anxiety disorders predicted by the longitudinal course of internalizing symptoms and parent-adolescent disagreements. Arch Gen Psychiatry. 1999; 56:726-32. [PubMed: 10435607]

74. Restifo K, Bögels S. Family processes in the development of youth depression: translating the evidence to treatment. Clin Psychol Rev. 2009; 29:294-316. [PubMed: 19356833]

75. Hawker DS, Boulton MJ. Twenty years' research on peer victimization and psychosocial maladjustment: a meta-analytic review of cross-sectional studies. J Child Psychol Psychiatry. 2000; 41:441-55. [PubMed: 10836674]

76. Patel V, Fisher AJ, Hetrick S, McGorry P. Mental health of young people: a global public-health challenge. Lancet. 2007; 369:1302-13. [PubMed: 17434406] 
77. Cluver L, Gardner F, Operario D. Psychological distress amongst AIDS-orphaned children in urban South Africa. J Child Psychol Psychiatry. 2007; 48:755-63. [PubMed: 17683447]

78. Jones L. Responding to the needs of children in crisis. Int Rev Psychiatry. 2008; 20:291-303. [PubMed: 18569181]

79. Eaves L, Silberg J, Erkanli A. Resolving multiple epigenetic pathways to adolescent depression. J Child Psychol Psychiatry. 2003; 44:1006-14. [PubMed: 14531583]

80. Lau JY, Eley TC. Disentangling gene-environment correlations and interactions on adolescent depressive symptoms. J Child Psychol Psychiatry. 2008; 49:142-50. [PubMed: 18211276]

81. Silberg J, Rutter M, Neale M, Eaves L. Genetic moderation of environmental risk for depression and anxiety in adolescent girls. Br J Psychiatry. 2001; 179:116-21. [PubMed: 11483472]

82. Caspi A, Sugden K, Moffitt TE, et al. Influence of life stress on depression: moderation by a polymorphism in the 5-HTT gene. Science. 2003; 301:386-89. [PubMed: 12869766]

83. Uher R, McGuffin P. The moderation by the serotonin transporter gene of environmental adversity in the etiology of depression: 2009 update. Mol Psychiatry. 2010; 15:18-22. [PubMed: 20029411]

84. Hariri AR, Drabant EM, Munoz KE, et al. A susceptibility gene for affective disorders and the response of the human amygdala. Arch Gen Psychiatry. 2005; 62:146-52. [PubMed: 15699291]

85. Risch N, Herrell R, Lehner T, et al. Interaction between the serotonin transporter gene (5HTTLPR), stressful life events, and risk of depression: a meta-analysis. JAMA. 2009; 301:246271. [PubMed: 19531786]

86. Rutter M, Thapar A, Pickles A. Gene-environment interactions. Biologically valid pathway or artifact? Arch Gen Psychiatry. 2009; 66:1287-89. [PubMed: 19996033]

87. Karg K, Burmeister M, Shedden K, Sen S. The serotonin transporter promoter variant (5HTTLPR), stress, and depression meta-analysis revisited: evidence of genetic moderation. Arch Gen Psychiatry. 2011; 68:444-54. [PubMed: 21199959]

88. Pine DS, Ernst M, Leibenluft E. Imaging-genetics applications in child psychiatry. J Am Acad Child Adolesc Psychiatry. 2010; 49:772-82. [PubMed: 20643311]

89. Casey BJ, Jones RM, Levita L, et al. The storm and stress of adolescence: insights from human imaging and mouse genetics. Dev Psychobiol. 2010; 52:225-35. [PubMed: 20222060]

90. Steinberg, L.; Dahl, R.; Keating, D.; Kupfer, D.; Masten, A.; Pine, D. The study of developmental psychopathology in adolescence: integrating affective neuroscience with the study of context. In: Cicchetti, D.; Cohen, D., editors. Developmental psychopathology. 2. Vol. 2. New York: Wiley; 2006. p. 710-41.

91. Feder A, Nestler EJ, Charney DS. Psychobiology and molecular genetics of resilience. Nat Rev Neurosci. 2009; 10:446-57. [PubMed: 19455174]

92. Forbes EE, Dahl RE. Neural systems of positive affect: relevance to understanding child and adolescent depression? Dev Psychopathol. 2005; 17:827-50. [PubMed: 16262994]

93. Brody AL, Saxena S, Silverman DH, et al. Brain metabolic changes in major depressive disorder from pre- to post-treatment with paroxetine. Psychiatry Res. 1999; 91:127-39. [PubMed: 10641577]

94. Pine DS. Developmental psychobiology and response to threats: relevance to trauma in children and adolescents. Biol Psychiatry. 2003; 53:796-808. [PubMed: 12725972]

95. Clauss JA, Cowan RL, Blackford JU. Expectation and temperament moderate amygdala and dorsal anterior cingulate cortex responses to fear faces. Cogn Affect Behav Neurosci. 2011; 11:13-21. [PubMed: 21264642]

96. Lopez-Duran NL, Kovacs M, George CJ. Hypothalamic-pituitary-adrenal axis dysregulation in depressed children and adolescents: a meta-analysis. Psychoneuroendocrinology. 2009; 34:127283. [PubMed: 19406581]

97. Goodyer IM, Herbert J, Altham PM, Pearson J, Secher SM, Shiers HM. Adrenal secretion during major depression in 8- to 16-year-olds, I. Altered diurnal rhythms in salivary cortisol and dehydroepiandrosterone (DHEA) at presentation. Psychol Med. 1996; 26:245-56. [PubMed: 8685281]

98. Guyer AE, McClure-Tone EB, Shiffrin ND, Pine DS, Nelson EE. Probing the neural correlates of anticipated peer evaluation in adolescence. Child Dev. 2009; 80:1000-15. [PubMed: 19630890] 
99. Forbes EE, Hariri AR, Martin SL, et al. Altered striatal activation predicting real-world positive affect in adolescent major depressive disorder. Am J Psychiatry. 2009; 166:64-73. [PubMed: 19047324]

100. Gotlib IH, Hamilton JP, Cooney RE, Singh MK, Henry ML, Joormann J. Neural processing of reward and loss in girls at risk for major depression. Arch Gen Psychiatry. 2010; 67:380-87. [PubMed: 20368513]

101. Institute of Medicine. Preventing mental, emotional and behavioral disorders among young people: progress and possibilities. Washington DC: National Academies Press; 2009.

102. Brennan PA, Le Brocque R, Hammen C. Maternal depression, parent-child relationships, and resilient outcomes in adolescence. J Am Acad Child Adolesc Psychiatry. 2003; 42:1469-77. [PubMed: 14627882]

103. Collishaw S, Pickles A, Messer J, Rutter M, Shearer C, Maughan B. Resilience to adult psychopathology following childhood maltreatment: evidence from a community sample. Child Abuse Negl. 2007; 31:211-29. [PubMed: 17399786]

104. Silk JS, Vanderbilt-Adriance E, Shaw DS, et al. Resilience among children and adolescents at risk for depression: mediation and moderation across social and neurobiological contexts. Dev Psychopathol. 2007; 19:841-65. [PubMed: 17705905]

105. Pargas RC, Brennan PA, Hammen C, Le Brocque R. Resilience to maternal depression in young adulthood. Dev Psychol. 2010; 46:805-14. [PubMed: 20604603]

106. Pickles A, Rowe R, Simonoff E, Foley D, Rutter M, Silberg J. Child psychiatric symptoms and psychosocial impairment: relationship and prognostic significance. Br J Psychiatry. 2001; 179:230-35. [PubMed: 11532800]

107. Klein DN, Shankman SA, Lewinsohn PM, Seeley JR. Subthreshold depressive disorder in adolescents: predictors of escalation to full-syndrome depressive disorders. J Am Acad Child Adolesc Psychiatry. 2009; 48:703-10. [PubMed: 19465876]

108. Khaw KT, Wareham N, Luben R, et al. Glycosylated haemoglobin, diabetes and mortality in men in Norfolk cohort of European prospective investigation of cancer and nutrition (EPIC-Norfolk). BMJ. 2001; 322:15-18. [PubMed: 11141143]

109. WHO. mhGAP intervention guide for mental, neurological and substance use disorders in nonspecialized health settings: mental health Gap Action Programme (mhGAP). Geneva: World Health Organisation; 2010.

110. Zuckerbrot RA, Cheung AH, Jensen PS, Stein RE, Laraque D. GLAD-PC Steering Group. Guidelines for adolescent depression in primary care (GLAD-PC): I. Identification, assessment, and initial management. Pediatrics. 2007; 120:e1299-312. [PubMed: 17974723]

111. Kroenke K, Spitzer RL, Williams JB. The Patient Health Questionnaire-2: validity of a two-item depression screener. Med Care. 2003; 41:1284-92. [PubMed: 14583691]

112. Borner I, Braunstein JW, St Victor R, Pollack J. Evaluation of a 2-question screening tool for detecting depression in adolescents in primary care. Clin Pediatr (Phila). 2010; 49:947-53. [PubMed: 20724330]

113. Richardson LP, Rockhill C, Russo JE, et al. Evaluation of the PHQ-2 as a brief screen for detecting major depression among adolescents. Pediatrics. 2010; 125:e1097-103. [PubMed: 20368315]

114. Goodman R. The strengths and difficulties questionnaire: a research note. J Child Psychol Psychiatry. 1997; 38:581-86. [PubMed: 9255702]

115. Daviss WB, Birmaher B, Melhem NA, Axelson DA, Michaels SM, Brent DA. Criterion validity of the mood and feelings questionnaire for depressive episodes in clinic and non-clinic subjects. $\mathrm{J}$ Child Psychol Psychiatry. 2006; 47:927-34. [PubMed: 16930387]

116. Kovacs M. The children's depression, inventory (CDI). Psychopharmacol Bull. 1985; 21:995-98. [PubMed: 4089116]

117. Verhulst, FC.; Ven der Ende, V. Using rating scales in a clinical context. In: Rutter, M.; Bishop, D.; Pine, D., et al., editors. Rutter's child and adolescent psychiatry. 5. Oxford: Blackwell; 2008. p. 289-98. 
118. Goodman R, Ford T, Richards H, et al. The development and well-being assessment: description and initial validation of an integrated assessment of child and adolescent psychopathology. $\mathrm{J}$ Child Psychol Psychiatry. 2000; 41:645-55. [PubMed: 10946756]

119. Lewinsohn PM, Klein DN, Seeley JR. Bipolar disorders in a community sample of older adolescents: prevalence, phenomenology, comorbidity, and course. J Am Acad Child Adoles Psychiatry. 1995; 34:454-63.

120. Costello EJ, Angold A, Burns BJ, Erkanli A, Stangl DK, Tweed DL. The Great Smoky Mountains study of youth. Functional impairment and serious emotional disturbance. Arch Gen Psychiatry. 1996; 53:1137-43. [PubMed: 8956680]

121. Hollis, C. Schizophrenia and allied disorders. In: Rutter, M.; Bishop, D.; Pine, D., et al., editors. Rutter's child and adolescent psychiatry. 5. Oxford: Blackwell; 2008. p. 737-58.

122. Brotman MA, Schmajuk M, Rich BA, et al. Prevalence, clinical correlates, and longitudinal course of severe mood dysregulation in children. Biol Psychiatry. 2006; 60:991-97. [PubMed: 17056393]

123. Costello EJ, Foley DL, Angold A. 10-year research update review: the epidemiology of child and adolescent psychiatric disorders: II. Developmental epidemiology. J Am Acad Child Adolesc Psychiatry. 2006; 45:8-25. [PubMed: 16327577]

124. Angold A, Costello EJ. Depressive comorbidity in children and adolescents: empirical, theoretical, and methodological issues. Am J Psychiatry. 1993; 150:1779-91. [PubMed: 8238631]

125. Moffitt TE, Caspi A, Taylor A, et al. How common are common mental disorders? Evidence that lifetime prevalence rates are doubled by prospective versus retrospective ascertainment. Psychol Med. 2010; 40:899-909. [PubMed: 19719899]

126. Angold A, Costello EJ, Erkanli A. Comorbidity. J Child Psychol Psychiatry. 1999; 40:57-87. [PubMed: 10102726]

127. Young JF, Mufson L, Davies M. Impact of comorbid anxiety in an effectiveness study of interpersonal psychotherapy for depressed adolescents. J Am Acad Child Adolesc Psychiatry. 2006; 45:904-12. [PubMed: 16865032]

128. Evans DL, Charney DS, Lewis L, et al. Mood disorders in the medically ill: scientific review and recommendations. Biol Psychiatry. 2005; 58:175-89. [PubMed: 16084838]

129. NICE Clinical Guideline CG28. Depression in children and young people: identification and management in primary, community and secondary care. National Institute for Health and Clinical Excellence; 2005.

130. Weisz JR, McCarty CA, Valeri SM. Effects of psychotherapy for depression in children and adolescents: a meta-analysis. Psychol Bull. 2006; 132:132-49. [PubMed: 16435960]

131. Klein JB, Jacobs RH, Reinecke MA. Cognitive-behavioral therapy for adolescent depression: a meta-analytic investigation of changes in effect-size estimates. J Am Acad Child Adolesc Psychiatry. 2007; 46:1403-13. [PubMed: 18049290]

132. Brent D, Emslie G, Clarke G, et al. Switching to another SSRI or to venlafaxine with or without cognitive behavioral therapy for adolescents with SSRI-resistant depression: the TORDIA randomized controlled trial. JAMA. 2008; 299:901-13. [PubMed: 18314433]

133. Mufson L, Dorta KP, Wickramaratne P, et al. A randomized effectiveness trial of interpersonal psychotherapy for depressed adolescents. Arch Gen Psychiatry. 2004; 61:577-84. [PubMed: 15184237]

134. Rosselló J, Bernal G. The efficacy of cognitive-behavioral and interpersonal treatments for depression in Puerto Rican adolescents. J Consult Clin Psychol. 1999; 67:734-45. [PubMed: 10535240]

135. Mufson L, Weissman MM, Moreau D, Garfinkel R. Efficacy of interpersonal psychotherapy for depressed adolescents. Arch Gen Psychiatry. 1999; 56:573-79. [PubMed: 10359475]

136. Hazell P, O'Connell D, Heathcote D, Robertson J, Henry D. Efficacy of tricyclic drugs in treating child and adolescent depression: a meta-analysis. BMJ. 1995; 310:897-901. [PubMed: 7719178]

137. Hetrick S, Merry S, McKenzie J, Sindahl P, Proctor M. Selective serotonin reuptake inhibitors (SSRIs) for depressive disorders in children and adolescents. Cochrane Database Syst Rev. 2007; 3:CD004851. [PubMed: 17636776] 
138. Goodyer I, Dubicka B, Wilkinson P, et al. Selective serotonin reuptake inhibitors (SSRIs) and routine specialist care with and without cognitive behaviour therapy in adolescents with major depression: randomised controlled trial. BMJ. 2007; 335:142. [PubMed: 17556431]

139. Goodyer IM, Dubicka B, Wilkinson P, et al. A randomised controlled trial of cognitive behaviour therapy in adolescents with major depression treated by selective serotonin reuptake inhibitors. The ADAPT trial. Health Technol Assess. 2008; 12:iii-iv. ix-60.

140. Emslie GJ, Ventura D, Korotzer A, Tourkodimitris S. Escitalopram in the treatment of adolescent depression: a randomized placebo-controlled multisite trial. J Am Acad Child Adolesc Psychiatry. 2009; 48:721-29. [PubMed: 19465881]

141. Bridge JA, Yengar S, Salary CB, et al. Clinical response and risk for reported suicidal ideation and suicide attempts in pediatric antidepressant treatment: a meta-analysis of randomized controlled trials. JAMA. 2007; 63:332-39.

142. Asarnow JR, Jaycox LH, Duan N, et al. Effectiveness of a quality improvement intervention for adolescent depression in primary care clinics: a randomized controlled trial. JAMA. 2005; 293:311-19. [PubMed: 15657324]

143. Fox CL, Butler I. Evaluating the effectiveness of a school-based counselling service in the UK. Br J Guidance Counselling. 2009; 37:95-106.

144. Sharan P, Gallo C, Gureje O, et al. World Health Organization-Global Forum for Health Research -Mental Health Research Mapping Project Group. Mental health research priorities in low- and middle-income countries of Africa, Asia, Latin America and the Caribbean. Br J Psychiatry. 2009; 195:354-63. [PubMed: 19794206]

145. Patel V, Fisher AJ, Hetrick S, McGorry P. Mental health of young people: a global public-health challenge. Lancet. 2007; 369:1302-13. [PubMed: 17434406]

146. Bolton P, Bass J, Betancourt T, et al. Interventions for depression symptoms among adolescent survivors of war and displacement in northern Uganda: a randomized controlled trial. JAMA. 2007; 298:519-27. [PubMed: 17666672]

147. Stice E, Shaw H, Bohon C, Marti CN, Rohde P. A meta-analytic review of depression prevention programs for children and adolescents: factors that predict magnitude of intervention effects. Consult Clin Psychol. 2009; 77:486-503.

148. Garber J, Clarke GN, Weersing VR, et al. Prevention of depression in at-risk adolescents: a randomized controlled trial. JAMA. 2009; 301:2215-24. [PubMed: 19491183]

149. Calear AL, Christensen H. Systematic review of school-based prevention and early intervention programs for depression. J Adolesc. 2010; 33:429-38. [PubMed: 19647310]

150. Saxena S, Maulik PK, Sharan P, Levav I, Saraceno B. Brief report - mental health research on low- and middle-income countries in indexed journals: a preliminary assessment. J Ment Health Policy Econ. 2004; 7:127-31. [PubMed: 15478991]

151. Patel V, Araya R, Chatterjee S, et al. Treatment and prevention of mental disorders in low-income and middle-income countries. Lancet. 2007; 370:991-1005. [PubMed: 17804058]

152. Engle PL, Black MM, Behrman JR, et al. the International Child Development Steering Group. Strategies to avoid the loss of developmental potential in more than 200 million children in the developing world. Lancet. 2007; 369:229-42. [PubMed: 17240290] 


\section{Search strategy and selection criteria}

We searched PubMed (Medline and life science journals) for articles in English using the search terms "adolescent depression" and "depression" (restricted to children), combined with additional search terms, specifically "epidemiology", "gender", "puberty", "diagnosis", "comorbidity", "aetiology", "life events", "psychosocial", "family", "trends", "genetics", "gene-environment interaction", "temperament", "resilience", "dysthymic disorder", "treatment", "medication", "CBT", "prevention”, “ imaging", "cortisol", "longitudinal", and "outcomes". We also examined published reviews in the past decade, National Institute for Health and Clinical Excellence guidelines on adolescents with depression, American Academy of Child and Adolescent Psychiatry practice guidelines, and Cochrane systematic reviews. We focused on papers from the past 5 years, but also included papers published in the past 10 years (if evidence was sparse), or published at any time (if they were particularly important). Nearly all the published papers were from high-income countries. 


\section{Panel: Criteria for ICD-10 depressive episode}

\section{Core symptoms (at least two must be present)}

- Depressed mood present for most of the day and almost every day

- Loss of interest or pleasure in activities

- Decreased energy or increased susceptibility to fatigue

\section{Associated symptoms}

- Loss of confidence or self-esteem

- Unreasonable feelings of self-reproach or excessive inappropriate guilt

- Recurrent thoughts of death or suicide, or any suicidal behaviour

- Diminished ability to think or concentrate

- Change in psychomotor activity, agitation, or retardation

- Sleep disturbance

- Change in appetite with corresponding change in weight

At least four of these symptoms must be present for 2 weeks to diagnose a mild depressive episode, six to diagnose a moderate depressive episode, or eight for a severe depressive episode.

ICD-10=international classification of diseases-10. 


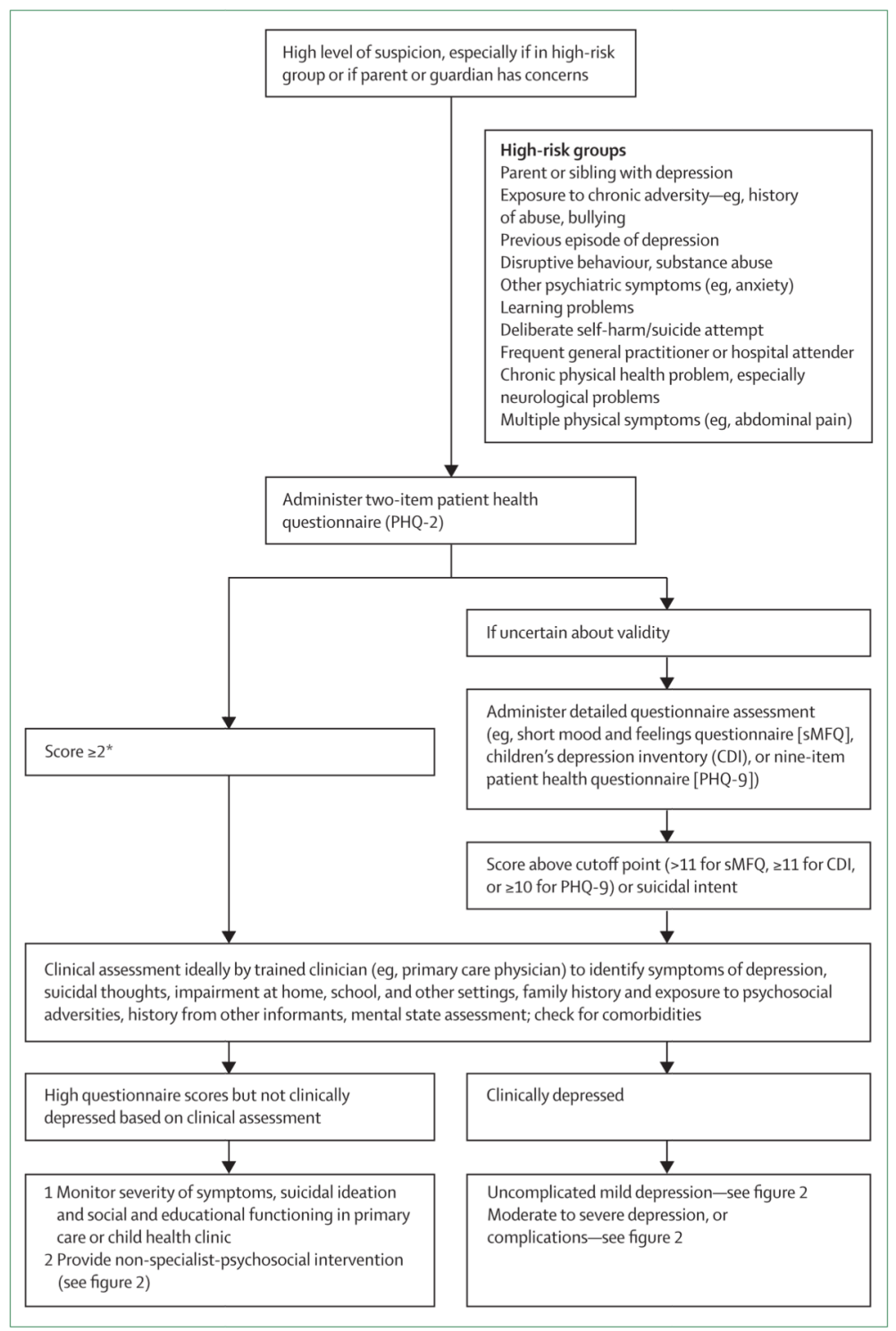

Figure 1. Detection of depression in adolescents in non-specialist settings

$*$ If patient scores $<2$, generally no further action is needed. 


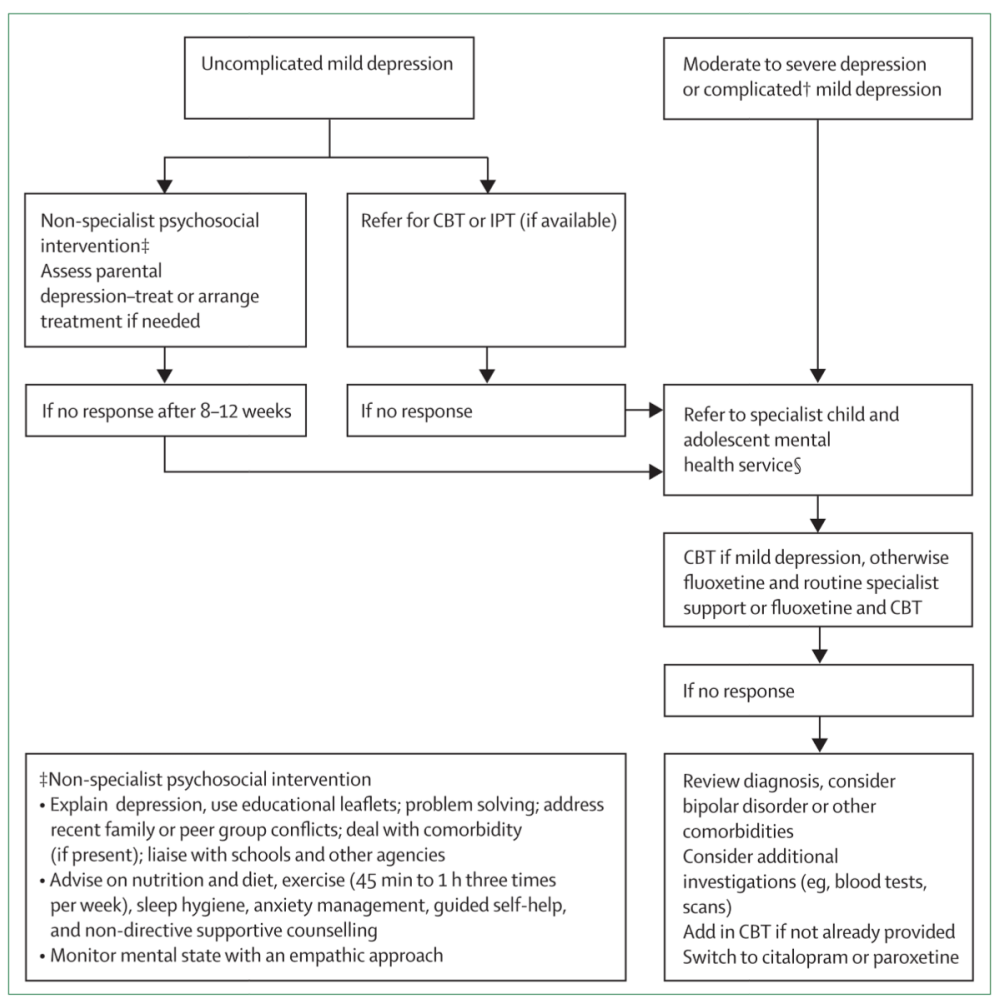

Figure 2. Treatment strategies for adolescents with depression*

$\mathrm{CBT}=$ cognitive behavioural therapy; IPT=interpersonal therapy. *Adapted guidance. ${ }^{10,129}$ Guidelines in different countries vary. ${ }^{\dagger}$ If no specialist services, treat mild depression with psychosocial strategies and moderate to severe depression with psychosocial strategies, medication, and careful monitoring. ${ }^{\S}$ Complications include comorbidities other than anxiety disorders (eg, eating disorders, substance misuse), suicide risk, and other medical and psychosocial factors that could make treatment with non-specialist psychosocial interventions difficult. 


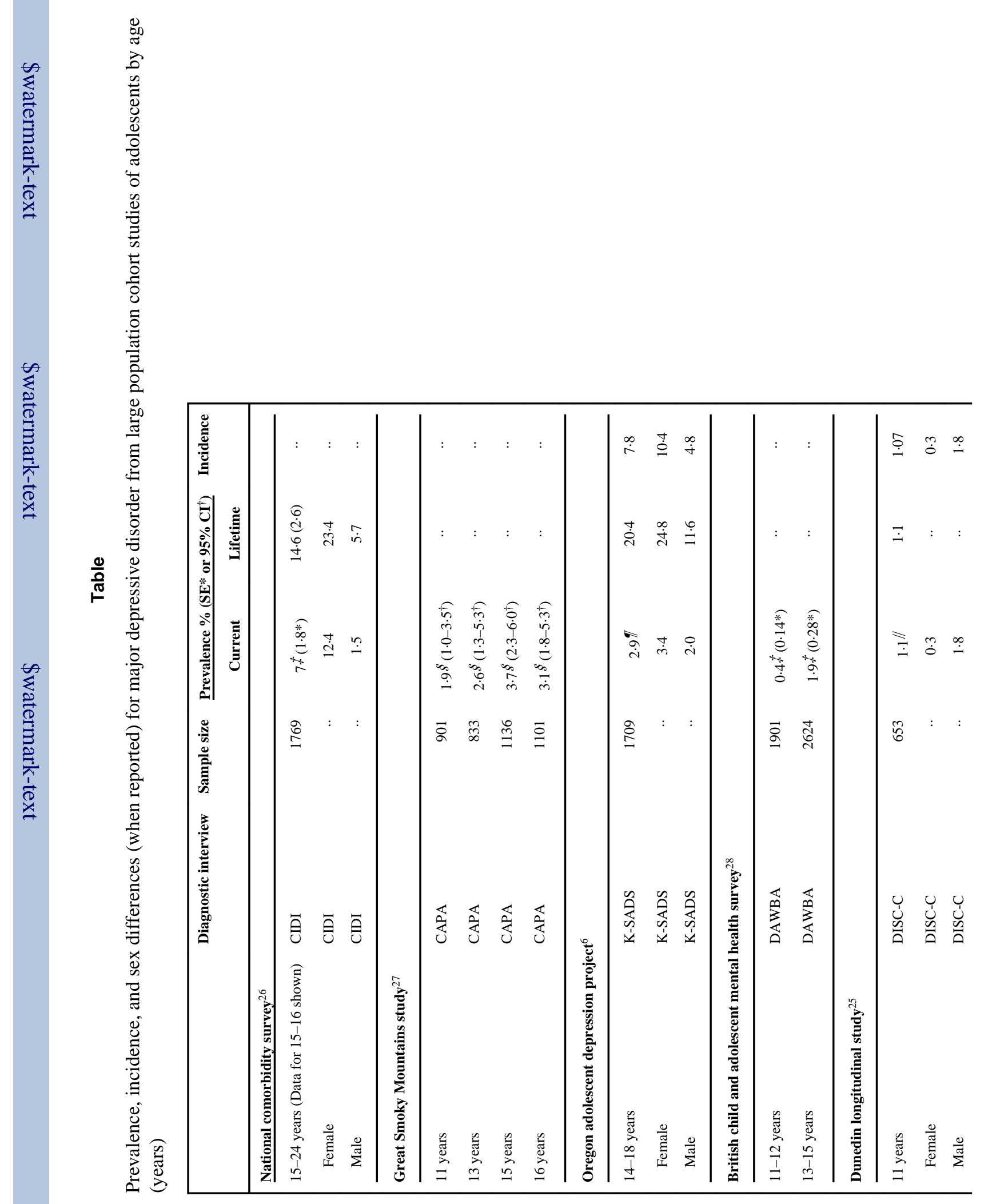

Lancet. Author manuscript; available in PMC 2012 November 03. 


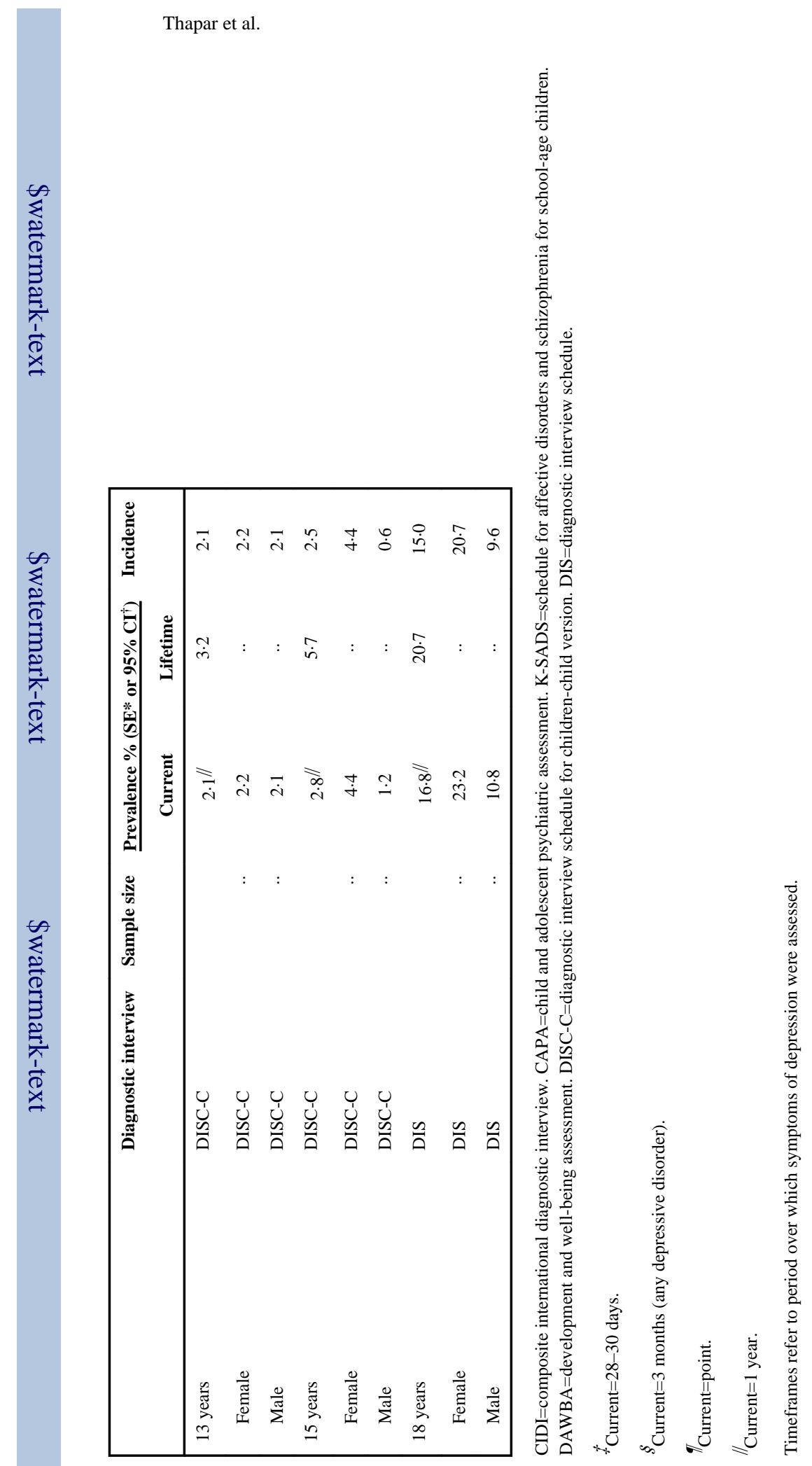

